vol.1 No.2 ISSN:18235-2014

\title{
Learning Needs Assessment for Patients Undergoing Bronchoscope Procedure
}

By

${ }^{1}$ Rasha Hassan Abass Shady, ${ }^{2}$ Wafaa Ismail Sherif Salam,

${ }^{3}$ Amira Ahmed Hassanin, ${ }^{4}$ Karima Elshamy.

1.2.3Medical-Surgical Nursing Department, Faculty of Nursing-Mansoura University

E-mail of corresponding author:

Rasha_za2000@yahoo.com

\begin{abstract}
:
Background Bronchoscopy plays a significant role in the diagnosis of a variety of pulmonary diseases, with low morbidity and rare mortality. The patient learning has appositive effects in decrease patient's anxiety, decrease incidence of complications; decrease the length of hospitalization and increase patient's cooperation therefore, Aim of the study: was to assess the learning needs for patients undergoing bronchoscope procedure at the study setting. Methods: Explorative descriptive research design was conducted in the" Bronchoscope Unit" at the Chest Department of the Mansoura University Hospital. The data were collected from convenient sample 150 patients of both sexes who correspond to inclusion criteria. Results: The results indicate that the majority of patients did not have knowledge about pre-procedure and post procedure preparations, post procedure complications, expected sensations from bronchoscope and how to manage the complications. It was noticed that patients need more information about these topics to help them to grants a sense of control and it can reduce anxiety, improve compliance, create realistic expectations, promote self -care and participation, and generate feeling of safety and security. Conclusion: The assessment of learning needs for patients undergoing bronchoscope clearly indicate that nurse need for a general teaching guideline to be used when dealing with bronchoscope patients to help patients, participation in achieving a successful outcome of the bronchoscope procedure and treatment plan.
\end{abstract}

Keywords: Learning needs, Patients, Bronchoscope

Introduction:

Bronchoscopy has assumed a central technique in the evaluation and management of pulmonary diseases, with low morbidity and rare mortality ${ }^{(1)}$. It can be defined as a diagnostic and therapeutic procedure that permits direct visualization of the tracheobronchial lumen with the help of the bronchoscope, a specialized optical device ${ }^{(2,3)}$. The use of bronchoscope, either for diagnostic purposes or for therapeutic procedures has increased worldwide. Diagnostic reasons for bronchoscope include visualization of tumors, obstructions, secretions, bleeding, or a foreign body in tracheobronchial tree, and to help diagnose bronchogenic carcinoma, 
Rasha Hassan Abass Shady..at.el.

tuberculosis, interstitial pulmonary disease, and fungal or parasitic pulmonary infection by obtaining a specimen for bacteriological and cytological examination. Therapeutic reasons involve removal of foreign bodies, malignant or benign tumors, mucus plugs, and excessive secretions from the tracheobronchial tree ${ }^{(1,4,5)}$.

Bronchoscopy is the most commonly used invasive procedure in clinical pulmonology. Currently it is estimated more than 10 million bronchoscopic procedures are performed each year in United States. In Europe, about 600,000 new cases of lung cancer are diagnosed each year with the help of bronchoscope. There is no national statistics about the number of bronchoscope procedure per year in Egypt, but some figure could be help as in New Kasr El Aini Teaching Hospital about 500 patients each year at the bronchoscope unit. Bronchoscope statistic in Mansoura university hospital in 2011 was 390 distributes as 293 were male and 97 were female, in 2012 was 303 distributed as 231 were male and 72 were female and in 2013 was 403 distributed as 290 were male and 1103 were female. In Mansoura city, Mansoura university hospital 401, bronchoscope procedures were done in year $2013^{(6,7)}$.
Complications of bronchoscopy is relatively rare and most often minor include major life threatening complications and minor non-life threatening complications. Major life threatening complications include respiratory depression, pneumonia, pneumothorax, airway obstruction, cardio respiratory arrest, arrhythmias, and pulmonary edema. While minor non-life threatening complications include, in order of frequency, vasovegal reactions, fever, cardiac arrhythmias, hemorrhage, airway obstruction, pneumothorax, nausea and vomiting $(1,8,9)$.

Classification for bronchoscope contraindications according to body system; it includes; cardiovascular contraindications such as recent myocardial infarction, unstable angina, unstable cardiac arrhythmias, severe hypertension, as well as severe carotid or cerebrovascular diseases. Pulmonary contraindications such as severe hypoxemia, hypoventilation with hypercarbia and severe bronchospasm or unstable asthma. Neurological contraindications such as active seizures, increased intracranial pressures and severe agitation. While the other medical conditions such as bleeding diathesis, platelets dysfunction or thrombocytopenia, severe anemia, cirrhosis with hypertension and 
uremia are Also contraindicated to procedure $^{(1,10)}$

Learning is the center of human ability to adapt, so all social institutions including health care make provision for teaching and learning; much learning (a persistent change in human performance or performance potential) is incidental to experience. Instruction is the deliberate arrangement of conditions to promote attainment of some intentional goal ${ }^{(12)}$.

Patient education is practiced using process of diagnosis and intervention, the needs assessment phase determines the nature of a need and motivation to learn and goals are mutually set with the patient. The goal of health education is to help individuals achieve optimum states of health through their own actions. Learning new information is based on previous knowledge and experience and each individual has the capacity to learn, learning ability varies from person to person and is situational ${ }^{(11)}$.

Learning the patients for diagnostic or therapeutic procedures has long been an accepted part of nursing practice Nurses are seeking ways to better prepare patients for health care procedures such as diagnostic tests more nurses that ever before in more specialized areas of care may not only assist with sophisticated diagnostic tests, but may order tests for patients and perform many procedures. Even when nurses do not perform or assist with some diagnostic tests they are generally responsible for preparing patients for tests performed in other areas and caring for these patients after the tests are completed. Through nurses are accustomed to providing physical; preparation for diagnostic tests and can do so readily, they may be less confident about intellectual and emotional preparation. These less tangible aspects of preparation are no less important ${ }^{(12)}$.

Nurses' responsibilities for patient undergoing bronchoscope include nurse role before, during, and after the procedure. Nurse's role before the procedure should cover preparation of necessary equipment, preparation of physical and psychological patient clinical condition, as well as, nurse's preparation to herself ${ }^{(13,14)}$. Nurses play an important role in the preparation of necessary equipment in order to save time and decrease incidence of complication which may occur for patient during the procedure. It includes preparation of necessary equipment for monitoring the patient during the procedure to facilitate early recognition of potential complication during the procedure, followed by preparation of necessary equipment and 
Rasha Hassan Abass Shady..at.el.

supplies for the procedure, and preparation necessary emergency equipment .equipment for monitoring patient includes cardiac monitor, ventilator, blood pressure cuff or arterial pressure monitoring, and pulse oximeter. equipment and supplies for the procedure such as fiber optics or rigid bronchoscope, light source, transbronchial needle aspiration, cytology brush, topical anesthesia , water soluble, lubricant, bite block, suction apparatus, $\mathrm{T}$ piece adapter ,oxygen source, cleaning and disinfectant solutions, specimen container as well as preparation of protective clothes . Emergency equipment includes patent I.V Cannulas, bag mask device capable of delivery of $100 \%$ oxygen and large inflation volumes, flow meter and intubation's equipment (15).

She should instructs the patient to perform good mouth care to decrease risk of introducing bacteria to lungs during procedure, ensure that patient remove metallic subject such as denatures and jewelry, assess last time for patient ingestion of food because the patient should have taken nothing by mouth for at least $6-8$ hours before the procedure. Immediately before the procedure commencement, the nurse should established intravenous access for patient, as well as, obtaining baseline vital signs, assessing respiratory status, measuring oxygen saturation, positioning patient according to physician preference or in supine position with head of the bed elevated 30 degree to provide easy access and facilitates visualization ${ }^{(16,17)}$. The nurse should determine patient allergies and then administer prescribed medication; atropine is given to dry secretions and to promote better visualization, it is used with precaution in patients with heart diseases. Patient should be given enough time to ask any question, express his concern and do breathing exercises as relation technique may be helpful for more relaxation and to decrease level of anxiety $(18,19)$

Nurses play an important role in assisting the physician throughout or during the procedure. Furthermore nurse assist patient during procedure with explanations the procedure step by step to decrease anxiety level and promote patient cooperation, assist the patient in maintaining proper position (supine with head hyper extended or semi fowler position). Also the nurse should monitor subjective response of patient to procedure, vital signs, respiratory status, and oxygen saturation, assess and monitor suctioned materials, capillary refill and color of nails bed. The nurse assist the physician with application of topical anesthesia to upper 
airways, (nose, pharynx), instruct the patient not to swallowing local anesthesia; provide emesis basin for expectoration local anesthetics. Moreover the nurse should be assist physician during bronchoscope procedure as requested because team efforts assist in performing the skill in a timely fashion. It includes; assisting in placement of $\mathrm{T}$ piece adapter if the patient is intubated to provide airtight seal around bronchoscope to minimize air leak and facilitate continued mechanical ventilation. As well as, lubrication, insertion and removal of bronchoscope step by step. Finally the bronchoscope nurse should complete processing by place tissue samples in properly labeled specimen containers containing formalin solution, and promptly transport the specimen to the laboratory for processing and analysis with corresponding patient demographics data, date and time of collection, and site of location, especially left or right lung ${ }^{(20,21)}$

\section{Observations}

and monitoring patient clinical condition although is an important aspect of nurse's role in the caring of patient after bronchoscope. On completion of the procedure, patients should observe closely in a designated recovery area that is adequately staffed and equipped with essential equipment and supplies. The patient is monitored in the procedure room approximately 30 minutes past the last dose of IV sedation by bronchoscope nurse ${ }^{(22,23)}$.The bronchoscope nurse places the patient into fowler's position, close monitoring of the patients oxygen saturation, vital signs and level of consciousness should be done and documented every five minutes. When oxygen saturations are greater than 92 percent, the patient is weaned off oxygen therapy according to doctor order. then in the recovery room the nurse assess and monitor patient clinical condition, vital signs, respiratory status, and neurological status every 15 minutes for 1 hour, then every 2 hours for 4 hours, then the nurse compare the result with baseline values . in addition the nurse should observe the patient to identify signs and symptoms of procedure risks ; such as delayed patient allergic reaction signs and symptoms (rash, urticaria , tachycardia, hyperpnea , hypertension, palpitations, nausea , or vomiting), pneumothorax signs and symptoms (dyspnea, tachypnea , anxiety, decrease breathing sounds or restlessness ), empyema signs and symptoms (fever, tachycardia, malaise, or elevated white blood cells count ), bleeding signs and symptoms (tachycardia , hypotension or restlessness), hemoptysis , 
Rasha Hassan Abass Shady..at.el.

difficulty breathing, cough, air hunger, excessive coughing, pain , or absent breathing sounds over the affected area . Furthermore, the nurse should notify the physician if any abnormalities occur and prepare emergency equipment to save patient life. Also the nurse should ensure that specimen are properly labeled and taken to laboratory for analysis ${ }^{(24,25)}$

Furthermore, the nurse should assess the patient's ability to swallow before allowing the patient to attempt liquids or solid foods before discharge, then instruct the patients to resume preoperative diet as directed by the health care practitioner, inform the patient that he or she may experience some sore throat and hoarseness, recognize anxiety related to test results, discuss the implications of abnormal test result on the patient's lifestyle, provide teaching information regarding the clinical implications of the test results as appropriate (26) . The bronchoscope nurse should reinforce information given by the patient's health care provider, inform the patient of smoking cessation programs as appropriate, and answer any questions voiced by the patient or family. Moreover before discharge: the bronchoscope nurse should remove IV line, review discharge instructions with the patient and family. Written instructions are provided since the medications used for conscious sedation may cause difficulty in remembering instructions. Finally the nurse should keep her record in the items related to the procedure name, duration of procedure, patient tolerance, and complications ${ }^{(26)}$

\section{Aim of the study:}

The study was conducted to assess the learning needs for patients undergoing bronchoscopy at the study settings.

\section{Subject and Method:}

\section{Material:}

\section{Design:}

Explorative descriptive research design was utilized to reach the aims of the study.

\section{Setting:}

The study was carried out in the", Bronchoscope Unit' at the Chest Department of the Mansoura University Hospital.

\section{Subject:}

The present study included 150 adult bronchoscope patients of both sexes, age ranging from 20-60 years, able to communicate verbally and who consented to participate in the study.

\section{Tools:}

One tool was used in this study for data collection:

"Bronchoscope patient structured interview sheet "include the following:

Part 1: Patients' socio demographic characteristics: 


This part consisted of
sociodemographic data, smoking habit and medical data this included ;age ,sex ,marital status ,residence ,occupation and educational level.

Part 2: This part constitutes structured items to identify patients' knowledge related to preparations for bronchoscope procedure, this part presents assessment of patients' knowledge related to bronchoscope preparation. It includes (pre procedure preparations, patient consent, reason for bronchoscope, duration of bronchoscope, medications to be given, laboratory investigations and radiological studies, mouth care before the bronchoscope, type of drugs stopping 3 days before procedure, fasting time, suitable time to start food and fluid intake after procedure, type of anesthesia used during procedure, post bronchoscope activity, diet.

\section{Methods:}

Official permission was obtained from the head of the chest department at the study setting to conduct the study. A verbal consent obtained from the respondents before their inclusion in the study. Nature and aim of the study was explained to each member of the participants.

The data were collected throughout the assessment sheet. All patients included in this study were interviewed individually twice, before and after the procedure, at sessions ranged from 30-45 minutes. Non hospitalized patients scheduled for bronchoscope procedure were initially interviewed immediately prior to the procedure in the waiting room - one hour prior the procedure. Hospitalized patients were initially interviewed one day prior to the procedure or on morning of the procedure. The first interview was conducted to elicit personal data from the patients. The second interview for both the hospitalized and non hospitalized patients was conducted after ascertaining that patients felt well enough to be interviewed. Thus the second interview was conducted on the average 2 to 3 hours after the end of the procedure. The second interview was conducted to assess learning needs of patients

\section{Statistical analysis:}

Data was analyzed using SPSS (Statistical Package for Social Sciences) version 13.0; Descriptive statistics was done using numbers, percentages, arithmetic mean, standard deviation as well as medians. Analysis of data was conducted using the Chi- square test of significance.

$\leq 0.05 \%$ level of significance was chosen.

\section{Results:}

The data collected were analyzed statistically and the results are 
Rasha Hassan Abass Shady..at.el.

categorized into 3 main parts which are: Assessment part, preparations for the bronchoscope examinations, Relation part

Table 1: This table illustrates that the largest proportion (59\%) of the patients were in the age group from $50<60$ years, while the lowest proportion $(7.33 \%)$ were in the age group from $20<30$ years. in relation to sex, males represent a higher percentage $(77.33 \%)$ in the study group; where female represent $(22.67 \%)$. The largest proportion $(76.0 \%)$ of the study patient was illiterate, while lowest proportion $(24.0 \%)$ of the patients was formally educated. Regarding residency place, higher proportions $(57.33 \%)$ lived in urban residence, while $(42.67 \%)$ were in rural residence. Regarding patient's occupation, the largest proportions (70.67) were involved in manual work; the lowest proportion (4\%) was unemployed. Regarding patient's diagnosis, the majority (40\%) were admitted with lung cancer. On the other hand $(38.67 \%)$ were diagnosed as pulmonary corpulmonale.

Table 2:This table revealed that patients have lack of knowledge in relation to the preparations for bronchoscope examination as (55.33\%, 97.33\%, 78\%, 70.67\%, $40.67 \%, 68 \%, 46.67 \%, 63.33 \%$ and $76.67 \%$ ) .Regarding preparations before bronchoscope, patient consent, reason for bronchoscope, duration of bronchoscope, type of anesthesia used during procedure, pre-bronchoscope medications, fasting time before the bronchoscope, type of drugs stopping 3 days before procedure , importance of mouth care before the bronchoscope, and importance of follow up after bronchoscope respectively.

Table 3: This table revealed that, there was a high statistical significant relation between education and need to learn about the preparations for bronchoscope procedure $\left(\mathrm{x}^{2}=113.706, \mathrm{P}=0.000\right)$, reason for bronchoscope examination $\left(\mathrm{x}^{2}=143.60, \mathrm{P}=0.000\right)$ , duration of bronchoscope procedure $\left(\mathrm{x}^{2}=228.90, \mathrm{P}=0.000\right)$, examination and laboratory investigations $\quad\left(\mathrm{x}^{2}=287.20\right.$, $\mathrm{P}=0.000$ ), need to learn about Medication received

before the procedure $\left(\mathrm{x}^{2}\right.$ $=17.00, \mathrm{P}=0.002)$, need to learn about importance fasting before examination $\left(\mathrm{x}^{2}=38.70\right.$, $\mathrm{P}=0.000)$, the importance of mouth care before the bronchoscope, $\left(\mathrm{x}^{2}=330.10, \mathrm{P}=0.000\right.$ ), positioning during the procedure ,$(\mathrm{X} 2=116.40, \mathrm{P}=0.000)$, type of anesthesia used during procedure, $\left(\mathrm{x}^{2}=73.40, \mathrm{P}=0.000\right)$, activity and diet allowed after bronchoscope , $\left(\mathrm{x}^{2}=112.20, \mathrm{P}=0.000\right)$, expected sensation after the procedure,,$\left(\mathrm{x}^{2}\right.$ $=21.80, \mathrm{P}=0.000)$, need to learn about ,post bronchoscope 
Learning Needs Assessment for Patients Undergoing Bronchoscope Procedure

complications and its management, mentioned topics above $\left(\mathrm{x}^{2}\right.$
$\left(\mathrm{x}^{2}=256.60, \mathrm{P}=0.000\right)$ and all $\quad=3.30, \mathrm{P}=0.509$.

Table (1): Distribution of the studied patients as regards their socio-demographic characteristics

\begin{tabular}{|c|c|c|}
\hline Variable & $\begin{array}{c}\text { Number } \\
(150)\end{array}$ & Percent $(\%)$ \\
\hline 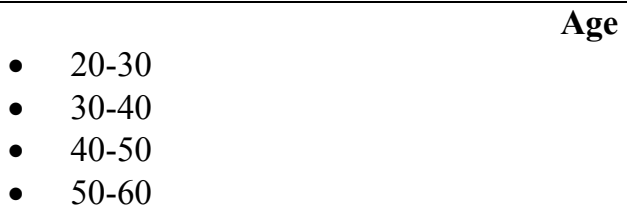 & $\begin{array}{l}11 \\
12 \\
44 \\
83\end{array}$ & $\begin{array}{c}7.33 \\
8 \\
25.57 \\
59\end{array}$ \\
\hline $\begin{array}{lll} & \text { Sex } \\
\text { - } & \text { Female } & \\
\text { - } & \text { Male } & \\
\end{array}$ & $\begin{array}{c}34 \\
116\end{array}$ & $\begin{array}{l}22.67 \\
77.33\end{array}$ \\
\hline $\begin{array}{lll} & \text { Marital status: } \\
\text { - } & \text { Single } & \\
\text { - } & \text { Married } \\
\text { - } & \text { Divorced } \\
\text { - } & \text { widow }\end{array}$ & $\begin{array}{c}10 \\
134 \\
4 \\
2\end{array}$ & $\begin{array}{c}6.67 \\
89.33 \\
2.67 \\
1.33\end{array}$ \\
\hline $\begin{array}{lll} & \text { Educational level } \\
\text { - } & \text { Illiterate } & \\
\text { - } & \text { Formally educated } & \\
\end{array}$ & $\begin{array}{c}114 \\
36 \\
\end{array}$ & $\begin{array}{l}76.0 \\
24.0\end{array}$ \\
\hline $\begin{array}{lll} & \text { Residence } \\
\text { - } & \text { Urban } & \\
\text { - } & \text { Rural } & \\
\end{array}$ & $\begin{array}{l}86 \\
64 \\
\end{array}$ & $\begin{array}{l}57.33 \\
42.67\end{array}$ \\
\hline $\begin{array}{lll} & \text { Occupation } \\
\text { - } & \text { Manual } & \\
\text { - } & \text { Cleric } & \\
\text { - } & \text { Unemployed } \\
\text { - } & \text { Housewife }\end{array}$ & $\begin{array}{c}106 \\
7 \\
6 \\
31\end{array}$ & $\begin{array}{c}70.67 \\
4.67 \\
4 \\
20.67\end{array}$ \\
\hline $\begin{array}{lll} & \text { Admission : } \\
\text { - } & \text { Out patient } \\
\text { - } & \text { Inpatient }\end{array}$ & $\begin{array}{l}81 \\
69\end{array}$ & $\begin{array}{l}54.0 \\
46.0\end{array}$ \\
\hline $\begin{array}{lll} & \text { Diagnosis } \\
\text { - } & \text { lung cancer } \\
\text { - } & \text { Pleural effusion } \\
\text { - } & \text { Lung abscess } \\
\text { - } & \text { Bronchiectasis } \\
\text { - } & \text { Pulmonary corpulmonale } \\
\end{array}$ & $\begin{array}{l}60 \\
14 \\
10 \\
8 \\
5\end{array}$ & $\begin{array}{c}40 \\
9.33 \\
6.67 \\
5.33 \\
38.67\end{array}$ \\
\hline
\end{tabular}


Rasha Hassan Abass Shady..at.el.

Table (2): Frequency distribution of bronchoscope patients in relation to their knowledge about the preparations for bronchoscope examination

\begin{tabular}{|c|c|c|}
\hline Variable & $\begin{array}{c}\text { Number } \\
(\mathbf{1 5 0})\end{array}$ & $\begin{array}{c}\text { Percent } \\
(\%)\end{array}$ \\
\hline $\begin{array}{ll} & \text { Know preparations before bronchoscope } \\
\text { - } & \text { Know } \\
\text { - } & \text { Don't know } \\
\end{array}$ & $\begin{array}{l}67 \\
83\end{array}$ & $\begin{array}{l}44.67 \\
55.33\end{array}$ \\
\hline Total & 150 & 100 \\
\hline Patient consent & $\begin{array}{c}4 \\
146 \\
\end{array}$ & $\begin{array}{c}2.67 \\
97.33\end{array}$ \\
\hline Total & 150 & 100 \\
\hline Know the reason for bronchoscope & $\begin{array}{c}33 \\
117\end{array}$ & $\begin{array}{l}22 \\
78\end{array}$ \\
\hline Total & 150 & 100 \\
\hline Know duration of bronchoscope & $\begin{array}{c}44 \\
106 \\
\end{array}$ & $\begin{array}{l}29.33 \\
70.67\end{array}$ \\
\hline Total & 150 & 100 \\
\hline $\begin{array}{l}\text { Know the type of anesthesia used during procedure } \\
\text { - } \quad \text { Know } \\
\text { - } \quad \text { Don't know }\end{array}$ & $\begin{array}{l}89 \\
61\end{array}$ & $\begin{array}{l}59.33 \\
40.67\end{array}$ \\
\hline Total & 150 & 100 \\
\hline $\begin{array}{ll}\text { Know the pre-bronchoscope medications } \\
\text { - } & \text { Know } \\
\text { - } & \text { Don't know }\end{array}$ & $\begin{array}{c}48 \\
102\end{array}$ & $\begin{array}{l}32 \\
68\end{array}$ \\
\hline Total & 150 & 100 \\
\hline $\begin{array}{l}\text { Know fasting time before the bronchoscope } \\
\text { - Know } \\
\text { - } \quad \text { Don't kno }\end{array}$ & $\begin{array}{l}80 \\
70\end{array}$ & $\begin{array}{l}53.33 \\
46.67\end{array}$ \\
\hline Total & 150 & 100 \\
\hline $\begin{array}{l}\text { Know the type of drugs stopping } 3 \text { days before procedure } \\
\text { - Yes } \\
\text { - } \quad \text { No }\end{array}$ & $\begin{array}{l}67 \\
83\end{array}$ & $\begin{array}{l}44.67 \\
55.33\end{array}$ \\
\hline Total & 150 & 100 \\
\hline $\begin{array}{l}\text { Know the importance of mouth care before the bronchoscope } \\
\text { - Know } \\
\text { - } \quad \text { Don't know }\end{array}$ & $\begin{array}{l}55 \\
95\end{array}$ & $\begin{array}{l}36.67 \\
63.33\end{array}$ \\
\hline Total & 150 & 100 \\
\hline $\begin{array}{l}\text { Know the importance of follow up after bronchoscope } \\
\text { - } \quad \text { Know } \\
\text { - } \quad \text { Don't know }\end{array}$ & $\begin{array}{c}35 \\
115\end{array}$ & $\begin{array}{l}23.33 \\
76.67\end{array}$ \\
\hline Total & 150 & 100 \\
\hline
\end{tabular}


Table (3): Relation between education and learning needs for bronchoscope patients

\begin{tabular}{|c|c|c|c|c|c|c|c|c|}
\hline \multirow[b]{2}{*}{$\begin{array}{l}\text { Important topics } \\
\text { needed to learn }\end{array}$} & & \multicolumn{5}{|c|}{ Education } & \multirow[b]{2}{*}{$\begin{array}{c}\text { Tot } \\
\text { al }\end{array}$} & \multirow[t]{2}{*}{$x^{2} p$} \\
\hline & & $\begin{array}{l}\text { Illiter } \\
\text { ate }\end{array}$ & $\begin{array}{c}\text { Read } \\
\& \\
\text { write }\end{array}$ & $\begin{array}{l}\text { Prep } \\
\text { arato } \\
\text { ry }\end{array}$ & $\begin{array}{c}\text { seco } \\
\text { nda } \\
\text { ry }\end{array}$ & $\begin{array}{l}\text { Uni } \\
\text { ver } \\
\text { sity }\end{array}$ & & \\
\hline \multirow{2}{*}{$\begin{array}{l}\text { Bronchoscope } \\
\text { procedure and effects }\end{array}$} & No & 2 & & & & & 2 & \multirow{2}{*}{$\begin{array}{l}3.30 \\
0.509\end{array}$} \\
\hline & $\%$ & 3.3 & & & & & 1.3 & \\
\hline \multirow{2}{*}{$\begin{array}{l}\text { Reason of } \\
\text { bronchoscope } \\
\text { examination }\end{array}$} & No & 19 & 13 & 1 & 1 & & 34 & \multirow{2}{*}{$\begin{array}{l}113.70 \\
0.000\end{array}$} \\
\hline & $\%$ & 31.7 & 22.4 & 7.1 & 12.5 & & 22.7 & \\
\hline \multirow{2}{*}{ Duration of procedure } & No & 12 & 11 & 2 & 2 & 2 & 29 & \multirow{2}{*}{$\begin{array}{l}143.60 \\
0.000\end{array}$} \\
\hline & $\%$ & 20 & 19 & 14.3 & 25 & 20 & 19.3 & \\
\hline \multirow{2}{*}{$\begin{array}{l}\text { Examination and } \\
\text { laboratory } \\
\text { investigations }\end{array}$} & No & 19 & 22 & 2 & 2 & 4 & 49 & \multirow{2}{*}{$\begin{array}{l}228.90 \\
0.000\end{array}$} \\
\hline & $\%$ & 31.7 & 37.9 & 14.3 & 25 & 40 & 32.7 & \\
\hline \multirow{2}{*}{$\begin{array}{l}\text { Medication received } \\
\text { before the procedure }\end{array}$} & No & 22 & 28 & 5 & 1 & 5 & 61 & \multirow{2}{*}{$\begin{array}{l}287.20 \\
0.000\end{array}$} \\
\hline & $\%$ & 36.7 & 48.3 & 35.7 & 12.5 & 50 & 40.7 & \\
\hline \multirow{2}{*}{$\begin{array}{l}\text { Fasting time before } \\
\text { examination }\end{array}$} & No & & 1 & & & 1 & 2 & \multirow{2}{*}{$\begin{array}{l}17.00 \\
0.002\end{array}$} \\
\hline & $\%$ & & 1.7 & & & 10 & 1.3 & \\
\hline \multirow{2}{*}{$\begin{array}{l}\text { Importance of mouth } \\
\text { care before the } \\
\text { procedure }\end{array}$} & No & 3 & 2 & 1 & 1 & & 7 & \multirow{2}{*}{$\begin{array}{l}38.70 \\
0.000\end{array}$} \\
\hline & $\%$ & 5 & 3.4 & 7.1 & 12.5 & & 4.7 & \\
\hline \multirow{2}{*}{$\begin{array}{l}\text { Positioning during the } \\
\text { procedure }\end{array}$} & No & 21 & 29 & 6 & 3 & 5 & 64 & \multirow{2}{*}{$\begin{array}{l}330.10 \\
0.000\end{array}$} \\
\hline & $\%$ & 35 & 50 & 42.9 & 37.5 & 50 & 42.7 & \\
\hline \multirow{2}{*}{$\begin{array}{l}\text { Type of anesthesia } \\
\text { used during procedure }\end{array}$} & No & 2 & 7 & 4 & 2 & 1 & 16 & \multirow{2}{*}{$\begin{array}{l}116.40 \\
0.000\end{array}$} \\
\hline & $\%$ & 3.3 & 12.1 & 28.6 & 25 & 10 & 10.7 & \\
\hline \multirow{2}{*}{$\begin{array}{l}\text { Activity and diet } \\
\text { allowed after } \\
\text { bronchoscope }\end{array}$} & No & 3 & 7 & 1 & 1 & 1 & 13 & \multirow{2}{*}{$\begin{array}{l}73.40 \\
0.000\end{array}$} \\
\hline & $\%$ & 5 & 12.1 & 7.1 & 12.5 & 10 & 8.7 & \\
\hline \multirow{2}{*}{$\begin{array}{l}\text { Expected sensation } \\
\text { after the procedure }\end{array}$} & No & 6 & 8 & 4 & 1 & 1 & 20 & \multirow{2}{*}{$\begin{array}{l}112.20 \\
0.000\end{array}$} \\
\hline & $\%$ & 10 & 13.8 & 28.6 & 12.5 & 10 & 13.3 & \\
\hline \multirow{2}{*}{$\begin{array}{l}\text { Post bronchoscope } \\
\text { complications and its } \\
\text { management }\end{array}$} & No & 2 & 2 & 1 & & & 5 & \multirow{2}{*}{$\begin{array}{l}21.80 \\
0.000\end{array}$} \\
\hline & $\%$ & 3.3 & 3.4 & 7.1 & & & 3.3 & \\
\hline \multirow{2}{*}{$\begin{array}{l}\text { All mentioned topics } \\
\text { above }\end{array}$} & No & 25 & 18 & 6 & 4 & 2 & 55 & \multirow{2}{*}{$\begin{array}{l}265.60 \\
0.000\end{array}$} \\
\hline & $\%$ & 41.7 & 31 & 42.9 & 50 & 20 & 36.7 & \\
\hline
\end{tabular}

Significant relation at level $\leq 0.05$ 


\section{Discussion:}

Bronchoscope procedure is a risky stressful procedure that might be followed by complications .stress derived from this procedure is magnified. It could stem from physical causes derived from the physical condition as well as psychological causes such as, fear from the unknown or from procedure itself. Patient's stress can lead to prolongation of the procedure and also may trigger some hindrance in the procedure steps leading to harmful effect on the patient. Bronchoscope procedure, as many other procedures, is threatening. Although it is not a painful procedure most patients find it extremely exhausting and uncomfortable. These feelings could be exaggerated if the patient does not receive the appropriate information about these procedures (26)

In the present study, regarding patient's age, the result revealed that, the largest proportion of the patients were in age group from $50<60$. This was congruent with Young and Hyun (2009) who stated that respiratory disease is rarely found in young patients, especially in those younger than 40 years of age. Another study done by Riley (2007), Vinolas (2008) and Mai Tran (2002) who reported that ; respiratory disease were found in people who are 50 years of age or older, with an average age at diagnosis of 60 years. ${ }^{(27,28,29,30)}$.

In relation to sex of patients undergoing bronchoscope, the present study findings revealed that male patients comprised higher proportion than females, this supported by Jemal(2007) who reported that the incidence of chest diseases are higher in males than females. Another study done by Parkin (2002) who mentioned that chest diseases are common in men and the fifth most frequent in women. ${ }^{(31,32)}$.

In this study more than one quarter of the study patients were illiterate, this is supported by Ebrahim (2005) and Hamdy (2009) who reported that the majority of patient diagnosed with lung cancer at the Main university Hospital were illiterate, they also added that in spite of that emphasis on patient education, it is observed that in Egypt it is greatly lacking. Some health professionals are arguing that the Egyptian patients, particularly the illiterate ones, are not in need of patient education .other health professionals are arguing that the Egyptian patients need only to learn about certain things, as diagnosis and medication. Patients however are adult who have the right to decide for themselves whether or not they need health education. ${ }^{(33,34)}$. 
Learning Needs Assessment for Patients Undergoing Bronchoscope Procedure

In addition, another study done by Hamdy (2009) and Ebrahim (2005) concluded that the majority of the studied patients were illiterate; they mentioned that the overwhelming characteristic of the Egyptian population is illiteracy and they do not have any formal education. The findings of the present study may be due to the setting of the study as free governmental hospital and the majority of patients having a low education and economical standards. Educated or highly educated patient are treated in private hospitals or in health insurance hospitals. ${ }^{(33,34)}$.

This study shows that, higher proportions were from urban area; this is related to inadequate health services in these places as reported by patient. This also can be considered as chest diseases related risk factors dealing with chemical substances which are used in farming. On the other hand this is in contrary with Liao (2007) who reported that chest diseases incidence rate had a tendency to reduce in urban areas. Vulnerable populations, such as the urban poor, are disproportionately affected by chest diseases. Poor persons face barriers accessing quality of respiratory care and when receiving care, may experience insensitivity to their plight. ${ }^{(35)}$
In the present study it was observed that the largest proportions were involved in manual work, such as building, farmer which makes patients exposed to chemical substances in working place and this patient had not health insurance services so admitted to the Mansoura University Hospital. This is supported by Minna (2006) who reported that repeated exposure to asbestos fibers, either at home or in the workplace makes workers exposed to chemicals in these places which were considered a risk factor for chest diseases. Another study done by Ali and Hussein (2010) reported that occupations are increasing the risk of getting lung cancer especially for some types of occupations.

The present study showed that majority of patients had insufficient information about the preparations for bronchoscope procedure it can be noticed that, lack of knowledge in relation to bronchoscope procedure in descending order as regarding bronchoscope procedure and effects, reason for bronchoscope examination, duration of bronchoscope procedure, examination and laboratory investigations, medication received before the procedure, fasting before examination, the importance of mouth care before the 
Rasha Hassan Abass Shady..at.el.

bronchoscope, positioning during the procedure, type of anesthesia used during procedure, activity and diet allowed after bronchoscope, expected sensation after the procedure, ,Post bronchoscope complications and its management.

Regarding preparation before the bronchoscope procedures the majority of the studied patients did not have knowledge about it. This is related to lack of communication and time spending with patient to given health teaching about preparation for procedure.

Result of the present study showed that, more than half of studied patients did not have knowledge about medication that must be stopped before the procedure at least 3 days; this finding is explained by the fact that the majority of the patients were illiterate.

Smelttzer and Bare (2009) mentioned that pre-procedural preparation and health teaching should include; completed patients chart containing consent, all laboratory reports and nurses records. Teach patient to leave jwellery. , contact lenses at home, and to wear loose fitting, comfortable clothes; a fasting period of 4-6 hours, psychological support and explanation of the procedure, teach patient breathing and leg exercises, provide patient instruction about pain management. While the finding of the current study revealed that more than half of the studied patients did not have knowledge about pre-procedural preparation and teaching for procedure, on the other hand the knowledgeable patients reported pre-procedural preparation in descending order as majority were fasting 6 hours and less than one quarter of patients reported consent, wear gown and having complete physical examination ${ }^{(38)}$

According to Mark and Phipps (2002) who stated that main important post -procedural care for patient undergoing bronchoscope should include preventing infection and bleeding, promote comfort, early ambulation, activity and providing emotional support. However, results of the present study concluded that majority of patients did not have knowledge about post -procedural items including preparations before the procedure, activity, nutrition, post bronchoscope complications, management of complications this finding is related to that patient's see the physicians once or twice during pre-procedure hospitalized period and nurse do not have time to give health teaching ${ }^{(39)}$

In relation to importance of laboratory investigations, more than one half did not have knowledge about value and importance of investigations; the physician did not have time to tell the patient about the importance of 
Learning Needs Assessment for Patients Undergoing Bronchoscope Procedure

investigations before the particular types of learning needs

bronchoscope procedure.

With regard to informed consent, the result is consistent with a study done in Egypt, which showed that informed consent is relatively meaningless to the Egyptian patients (Naguib, 2006). Since it is assumed by many patients that being hospitalized implies that they are willing to undergo any necessary procedure .Furthermore, patients may believe that the informed consent is an administrative thing which does not entail any informative responsibility on the part of the health members .furthermore, Vertinsky (2002) found that most patients do not want to take full responsibility for making their own medical decisions. Patients may desire to participation in the decision -making process, they do not want to make the decisions .Another reason the patients may be believes, in so much that they are more accepting of whatever comes to them. Moreover the physician holds all of the power of health care decisions .Also; many patients may not want to be responsible for decisions that may ultimately lead to unfavorable outcomes ${ }^{(40,41)}$.

As regards relation between education and preparations for bronchoscope examination the current study revealed that there was high relationship between level of education and the need for a and information related bronchoscope procedure and effects, reason for bronchoscope examination, duration of bronchoscope procedure, examination and laboratory investigations, need to learn about medication received before the procedure, need to learn about importance Fasting before examination, the importance of mouth care before the bronchoscope, positioning during the procedure, type of anesthesia used during procedure, activity and diet allowed after bronchoscope , expected sensation after the procedure, need to learn about ,post bronchoscope complications and its management .this is in agreement with Davison et al (2007) ,Galloway et al (2002),Bilodeau and Degner (2001) who found relationships between level of education and need for a particular type of information . Bilodeau and Degner (2001) stated that patients with lower level of education wanted more information about risk for chest diseases and wanted for bronchoscope. In contradiction, Degner et al (2001) were found no relation between level of education $\underset{(42,43,44)}{\text { and }}$ type of information needs. 


\section{Conclusion:}

Based on findings of the current study, it can be concluded that bronchoscope patients had lack of knowledge and/or misconceptions about the preparations for procedure it was found that; more than two third of patients had lack of knowledge about bronchoscope procedure and effects, duration of procedure, in addition more than half of patient did not have knowledge about effect of smoking ,pre-procedure preparations and teaching, post procedure care and teaching .while more than one third of patients had lack of knowledge about medication received before procedure, positioning during procedure , while less than one third did not have knowledge about post bronchoscope complications, manage chest pain, cough, while more than half did not have knowledge about management of dyspnea, and hemoptysis. Likewise the majority of patients did not have knowledge about preprocedure and post procedure care, post procedure complications, expected sensations from bronchoscope and mange the complications. It was noticed that patients need more information about these topics to help them to grants a sense of control and it can reduce anxiety, improve compliance, create realistic expectations, promote self -care and participation, and generate

feeling of safety and security

\section{Recommendations:}

The current study projects the following recommendations:

1. Establish a health education team comprising medical and qualified professional nursing staff; allow time to talk with the patients and provide information related to procedure ,management and appropriate self care management according to identified patients' needs

2. A suitable learning program should be adopted this program should include the procedure steps and the importance of bronchoscope procedure to health condition of the patient.

3. Hand out booklets should be available whenever the patient needs more clarification about the procedure

4. Visual aids should be used to help patients during the learning process

5. The undergraduate programs for all level of nursing staff should emphasize the importance of patients learning an integral part of nursing care.

6. Nurses at all levels should receive training programs about ,how to plan, and implement patient's learning 
Learning Needs Assessment for Patients Undergoing Bronchoscope Procedure

Acknowledgements:

We would like to thank all the patients' who participated in the study and bronchoscope staff of the chest unit for their help and cooperation during the study period and appreciate the great efforts of our supervisors in this work.

\section{Corresponding author:}

Rasha Hassan Abass Shady Medical Surgical Nursing Department, Faculty of NursingMansoura University.

\section{References:}

1. Murray J., Nadel J (2005). Textbook of Respiratory Medicine. 8th ed. Philadelphia, Saunders; chap 22.

2. Allen J (2009). Bronchoscopy. Available at: http://www.nlm.nih.gov/medlin eplus/ency/article/003857.htm.

3. Fishman A (2010). Fishmans's pulmonary diseases and disorders. 3rd ed, New York, McGraw- Hill: 437- 65.

4. Felix J, Herth F., Ralf E, Armin E (2007). The Future of Bronchoscopy in Diagnosing, Staging and Treatment of Lung Cancer, available at:www.content.karger.org.com /produktedb/produkte.asp?typ $=\mathrm{f}$ ulltext\&file $=$ RES20060730043 99.

5. Bare B, Hinkle J (2008). Bronchoscopy overview, $\mathrm{h}$ ://www.uptodateonline.com/pa tients/content/topic.dttpo?topic Key= 1EbRR6s.pyijeXE.
6. Redman B (2009). Process of patient teaching in Nursing, 3th ed. Philadelphia: Lippincott Company, 121.

7. Talaska F, Marshall B (2009). A manual of Laboratory and Diagnostic Tests, 7th ed, Philadelphia, A Wolters Kluwer, 820- 26.

8. British Thoracic Society (2009). Guidelines on diagnostic flexible bronchoscopy, available at: http://www.thorax.bmj.com/cgi /content/full/56/suppl_1/i1?ijke $\mathrm{y}=7 \mathrm{f} 563 \mathrm{~d} 34 \mathrm{~b} 49 \mathrm{~d} 134 \mathrm{fe} 11$ eaf120 fa9ec13cc511687\&keytype $2=\mathrm{tf}$ ipsecsha.

9. American Thoracic Society, Bronchoalveolar Lavage (2010). Available at: http://www.thoracic.org/clinical /critical-care/atlas-of-criticalcareprocedures/bronchoalveolarlavage.php .

10. Kraft M (2011). Approach to the patient with respiratory disease. In: Goldman L, Austell D, eds. 23rd ed. Philadelphia: Saunders Elsevier; chap 83. Available at: http://www.nlm.nih.gov/medlin eplus/ency/article/003857.htm .

11. Wujcik D (2007). Human Interaction Is Key to Effective Patient Education .ONS Connect, (22) 5: 5

12. McHugh NG, Christmar N, Johnson JE (2011). 
Rasha Hassan Abass Shady..at.el.

Preparatory Information: What helps and why American Journal of Nursing; 5:780-782.

13. Pender NJ (2005). Patient identification of health information received during hospitalization. Nursing Research,; 23:262-267.

14. Martin JM (2004). Developing and implementing the role of the nurse bronchoscopist, Available at: http://avg.urlseek.vmn.net/searc h.php? $\mathrm{lg}=\mathrm{en} \& \mathrm{mkt}=\mathrm{en} \& \mathrm{type}=\mathrm{dn}$ $\mathrm{s} \& \mathrm{tb}=\mathrm{ie} \& \mathrm{tbn}=$ avg \&q$=\mathrm{www} \% 2$ Encbi\%2Enlm\%2Enih\%2Egov

15. Fuehner T., Lueders D., Niedmeyer J., Ziesing S., Welte T. Hoeper M (2009). Evaluation of a 24hour emergency bronchoscopy service in a tertiary care hospital, Available at: http://www.ncbi.nlm.nih.gov/pu bmed/19443517.

16. Lippman M, Kasper D, Fauci A, Longo D, Braunwald E, Hauser S, Jameson L (2012). Harrison's Principles of Internal Medicine, 16th ed., Philadelphia, McGraw-Hill Professional, , 517-23.

17. Sharon E, Preeman E (2011). From Wikipedia, Bronchoscopy. Available at: http://en.wikipedia.org/wiki/Br onchoscopy.

18. Lesser S (2008). Bronchoscopy for the New Endoscopy Nurse.
Available at:

http://www.endonurse.com/.

19. Loeb S (2001). Illustrated Guide to Diagnostic Tests. Philadelphia, USA. Springhouse Corporation, 25459.

20. Pagana KD, Pagana TJ (2005). Diagnostic testing and nursing implications: A case study Approach. 2nd ed Saint Louis: C .V. Mosby Co.,; VIIVIII: 51-64.

21. Ramsey AH, Oemig TV, Davis JP, Massey JP, Török TJ (2002). An outbreak of bronchoscopy-related

Mycobacterium tuberculosis infections due to lack of bronchoscope leak testing. Chest; 121:976-981.at: http://ajrccm.atsjournals.org/cgi /ijlink? linkType $=$ ABST \&journa 1 Code $=$ chest\&resid $=121 / 3 / 976$.

22. Lefever kee $J$, Liang $H$ (2006). Laboratory and diagnostic tests with nursing implications, New Zealand, Appleton-crofts. 330-34.

23. Annama J, Rekha R, Jadah $F$ (2012). Clinical nursing procedure ' the art of nursing practice'. New Delhi, medical publisher, $387-89$.

24. Hartshorn C, Sole M, Lamborn M (2000). Introduction to Critical Care Nursing. 2nd ed. London: W.B. Saunders Company; 49. 
Learning Needs Assessment for Patients Undergoing Bronchoscope Procedure

25. Bourne H, Neumann $C$ (2010). An audit of bronchoscopy practice in the United Kingdom: a survey of adherence to national guidelines, available at: http://www.chestjournal.org/cgi /content/full/128/3/1742

26. Rice H.V, Goldewel M, Batter $\mathrm{S}$, Robinson $\quad P$ (2004).' Relaxation Training and Response to Bronchoscope Procedure: A pilot Study "Nursing Research; 35(1):3943.

27. Young L, Hyun L, Ji-Youn $\mathbf{H}$, Heung $H$ (2009).lung cancer in patients younger than 40 years of age: imaging characteristics' at multidetector row CT. Journal of Thoracic oncology ; 2) 8:533-34.

28. Riely J, Seshan V, Azzoli C, Mark G (2007). Medical Surgical Nursing, Critical thinking in client care, Addison Wesley, New York ; 2)8:454.

29. Vinolas N, Dolores I, Felip E, pilar $G$ (2008). Gender Differences in non -small cell lung cancer (NSCLC) patients: A retrospective study based Spanish lung cancer Group (SLCG) trials .Journal of Thoracic Oncology ; 2)8:53334

30. Mai Tran G (2002). Bronchoscope .Available at: http://WWW.amswer.com/libra
ry/Alternative $\% 20$ Medicine $\% 2$

0Encyclopediua-cid-1832817.

31. Jemal A ,Siegel $R$, Ward E ,Murry T,Xu J ,Thun $M$ (2007) Bronchoscope Statistics .CA: Bronchoscope Journal For Clinicians ;57:4366

32. Parkin D , Pisani P, Ferlay J (2002).Estimate of the world wide incidence of 25 Major Cancers .International Journal of Cancer ;80:827-841.

33. Ebrahim N (2005). Identification of preoperative stressors as perceived by the hospitalized patients at main university hospitals of Alexandria .unpublished MSC. Thesis, Higher Institute of Nursing, University of Alexandria.

34. Hamdy N (2009). Nurses practices regarding the implementation of safety measuring in the critical care units, unpublished thesis, Faculty of Nursing. University of Alexandria

35. Liao M,Chen $Z$, Zheng $Y$ .Study of incidences ,time trends of female lung diseases ,survivals and its predictive factors on Shanghi population .Journal of thoracic Oncology ;(2) $8: 383$

36. Ali C, Hussein G (2010). The effect of nursing intervention on the condition of patient undergoing gastrointestinal 
Rasha Hassan Abass Shady.at.el.

endoscopy, unpublished thesis, Faculty of Nursing. University of Alexandria.

37. Minna D (2006). An ecological study of the association of metal air pollutants with lung diseases incidence in Texas .Journal of thoracic Oncology; 1(7):654-661.

38. Smelttzer S, Bare B (2009).Brunner Medical Surgical Nursing .10th ed .Philadelphia: Lippincott Company; 269-320, 1084-88.

39. Phipps W,Mark J (2002) .Medical Surgical Nursing Health and Illness Perspectives.7th ed. St Louis : The C.V Mosby Company; 1004-7..

40. Naguib H (2006). Physicians nurses and hospitalized patients perceptions of the surgical patients, educational rights .Doctoral Thesis of Alexandria. University of Alexandria .Higher Institute of Nursing.

41. Vertinsky IB, Thompson WA ,Uyeno D (2002). Measuring
Consumer desire for participation in clinical decision making .Health Services .Research ;9:121-134.

42. Davison J ,Gleave $M$ ,Goldenberg $\mathrm{S}$,Degner L,Hoffart D ,Berekowitz J (2007). Safety Management Committee, Japan Society for Respiratory Endoscopy, Bronchoscopy in Japan: A survey by the Japan Society for Respiratory Endoscopy. Available at: http://www3.interscience.wiley. com/cgibin/fulltext/121661801/ PDFSTART .

43. Galloway S, Gray don J, Harrison D, Evans-Boyden B, and Palmer -Wickham S (2002). Critical care nursing, diagnosis and management, 3rd ed, London, Mosby Company

44. Bilodeau B, Degner L (2001). Information needs sources of information, and decisional roles in women undergoing bronchoscope Nursing forum; 23:691-96. 